\title{
Validation and application of a numerical approach for the estimation of drag and churning losses in high speed roller bearings
}

\author{
Wenjun GAO $^{\mathrm{a}, \mathrm{b}, *}$, Yaguo LYU ${ }^{\mathrm{a}}$, Zhenxia LIU ${ }^{\mathrm{a}}$, Daniel NELIAS ${ }^{\mathrm{b}}$ \\ ${ }^{a}$ School of Power and Energy, Northwestern Polytechnical University, Xi'an, China \\ ${ }^{b}$ Univ Lyon, INSA-Lyon, CNRS, UMR5259 LaMCoS, F-69621, France
}

\begin{abstract}
A numerical-based model is proposed to estimate drag and churning losses in high speed roller bearings, which is caused by the rotation and translation of the rollers in the fluid environment inside the bearing. Three existing models for the total hydraulic loss prediction are used to validate the numerical approach, including the SKF model, the Palmgren model, and the Parker model. After that, the validated model is employed to analyze drag and churning losses of counter-rotating roller bearings, having obvious advantage over the other three models. Results show that the numerical model is close to the Parker model and partly similar with the SKF model if the supply of the lubricant oil is sufficient. And the estimated result by the Palmgren model is always the lowest. For the counter-rotating roller bearing, it is demonstrated that the drag and churning losses are rather serious due to its two rings rotating together, and they are related to the bearing supporting design. This is of importance for the intershaft supporting application in turbine engine where precise lubricating system design is a big challenge.
\end{abstract}

Keywords: Roller bearings; drag loss; churning loss; model validation; counter-rotating

\footnotetext{
* Corresponding author

Email address: gaowenjunn@yahoo.com (Wenjun GAO)
} 


\section{Introduction}

In a rotating machinery system like turbine engine, roller bearings play a key element since they support rotating shafts and rotors. Understanding heat generation mechanisms is a major issue for high speed roller bearings (such temperature due to excessive power losses within the bearing adversely impact its contact fatigue and scuffing failure modes [1]. In addition, the bearings play an important role for the fuel consumption and the CO2 emission since they contribute up to $10 \mathrm{~kW}$ per bearing to the total power losses within the oil required, as well as the capacity of the total lubrication system [2].

For the roller bearing, a small part of the oil is used to lubricate the contact zone and most of the oil is used to take away the heat. Larger amounts of oil can definitely enhance the heat dissipation. However, the increase of oil Further, the oil also acts as a heat source for high speed application, named as the windage drag and churing losses, which may constitute a relatively large portion of the bearing's total power loss (up to $50 \%$ for high speed applications). These losses are caused by a host of factors as a result of oil/air drag force and churning moments on the bearing element's surface [3]. Generally, the force exerted on the bearing element as it translates through the lubricant with the cage is called drag. It results from the shear stress by the lubricant viscosity and the compressive stress on the element. Those stresses are exerted contrary to the rolling direction of the element and form the drag force [4]. And the moment imposed due to rotation of the element in the lubricant is called churning. It is mainly caused by the shearing of the oil at the rolling element surface.

While there have been a large body of work dealing with mechanical friction losses in roller bearings $[5,6]$, there are only a few studies available on modeling the drag and churning losses, or named hydraulic losses. For drag force, Harris

used the result of one isolated element in an infinite medium, which is two- 
dimensional and ignored the effect of all surroundings [7]. This model is too simplified to represent the real bearing configuration. For churning moments, the various approaches used could only provide a rather gross approximation, only to establish general trends in a parametric design study $[8,9]$. And in view of the complicated internal geometry of the bearing and the operating environment, it is impossible to distinguish these two contribution of hydraulic losses by experimental tests [10]. So that both the effects of drag and churning are merged to one viscous or load-independent torque in many existing bearing friction models, where the Palmgren model and the SKF model are the most used. Besides, Parker employed the model in the program SHABERTH for the viscous loss calculation, to predict thermal performance of bearings.

In addition, for the drag and churning losses investigation, there is an assumption used that all bearing elements are completely submerged in a uniform fluid. However, for most bearing applications, only a small fraction of the bear45 ing cavity is filled with the oil [11]. To solve this problem, in most bearing simulation tools, an empirical adjustment factor is used to simply adjust the applicable fluid density [12]. To improve the predicting performance, Parker developed an equation to predict the oil volume percent inside the bearing cavity, despite the model he used to calculate the viscous loss is from Harris, which has been proven to be too simplified [13].

In the last years, the authors proposed several formulas for the drag force and churning moments prediction in roller bearings, based on a series of numerical investigation [14, 15]. In addition, an equation is derived to estimate the oil volume fraction inside the bearing with under-race lubrication, based on the oil/air two-phase flow simulation. It is defined as a function of oil flow rate, oil property and rotating speeds. In this article, these numerical-based formulas are employed to predict the drag and churning losses in roller bearings, and the results are compared with three existing hydraulic losses prediction models to verify its capability, e.g. Palmgren model, SKF model, and Parker model. Then the validated numerical model is applied to predict drag and churning losses in a special counter-rotating roller bearing, which is beyond the capacity of the 
three existing models.

\section{Existing hydraulic losses prediction models}

There have already been quite a few investigations of bearing friction torque

65 [16]. Palmgren [17] presented a bearing model of friction torque and divided it into load-independent torque and load-dependent torque. SKF presented their model of bearing power loss by experimental fitting and gave some recommended values for the parameters in their equations [18]. These models come from plenty of experimental studies and the results have been reduced to a simple model,

70 in which the hydraulic losses or load-independent losses are accounted as a seperated part.

\section{Palmgren model}

According to Palmgren, the bearing friction torque is divided into two parts which are load-independent friction torque and load-dependent friction torque.

75 After converting the units of load-independent friction torque from $\mathrm{kg} / \mathrm{mm}$ to $\mathrm{N} / \mathrm{m}$, the equation of load-independent friction torque of the bearing when lubricated by oil is shown in Equation 1.

$$
\left\{\begin{array}{cc}
M_{0}=1.5572 \times 10^{-6} f_{0} p d_{m}^{3} & \text { if } \frac{\eta \omega}{p}<2 \times 10^{-6} \\
M_{0}=9.81 \times 10^{-3} f_{0} p d_{m}^{3}\left(\frac{\eta \omega}{p}\right)^{\frac{2}{3}} & \text { if } \frac{\eta \omega}{p} \geq 2 \times 10^{-6}
\end{array}\right.
$$

Then the method of Palmgren was used by Harris but the values of parameters were updated.

$$
\begin{cases}M_{v}=10^{-10} f_{0}\left(v_{0} n\right)^{\frac{2}{3}} d_{m}^{3} & v_{0} n \geq 2000 \\ M_{v}=160 \times 10^{-10} f_{0} d_{m}^{3} & v_{0} n<2000\end{cases}
$$

Where $v_{0}$ is the kinematic viscosity, cSt; $n$ is the bearing rotating speed, $\mathrm{rpm} ; d_{m}$ is the pitch diameter of the bearing, $\mathrm{mm} ; f_{0}$ is the factor depending on bearing design and lubricating method in Palmgren model (for cylindrical roller bearing $=2-3$ ) and Harris model (for cylindrical roller bearing $=2.2-$ $4)$.

\section{SKF model}


According to SKF, the friction torque of bearings can be divided into four parts. Load-independent friction torque can be divided into friction torque of seals and friction torque of drag losses, churning, splashing etc. Load-dependent friction torque can be divided into rolling friction torque and sliding friction 90 torque. And the hydraulic losses (named drag loss by SKF) could be calculated as following.

$$
\begin{gathered}
M_{\text {drag }}=4 \times 10^{-3} V_{M} K_{\text {roll }} C_{w} B d_{m}^{4} n^{2}+1.093 \times 10^{-10} n^{2} d_{m}^{3}\left(\frac{n d_{m}^{2} f_{t}}{\nu}\right)^{-1.379} R_{s} \\
K_{\text {roll }}=\frac{K_{L} K_{Z}(d+D)}{D-d} 10^{-12} \\
C_{w}=2.789 \times 10^{-10} l_{D}^{3}-2.786 \times 10^{-4} l_{D}^{2}+0.0195 l_{D}+0.6439 \\
f_{t}=\left\{\begin{array}{c}
\sin _{D}(0.5 t) \quad 5 \frac{K_{L} B}{d_{m}} \\
1 \quad \text { when } 0 \leq t \leq \pi \\
\text { when } \pi<t<2 \pi \\
R_{s}=0.36 d_{m}^{2}(t-\sin t) f_{A} \\
t=2 \cos ^{-1}\left(\frac{0.6 d_{m}-H}{0.6 d_{m}}\right) \quad \begin{array}{l}
\text { When } H \geq d_{m}, \text { use } H=d_{m} \\
f_{A}=0.05 \frac{K_{Z}(D+d)}{D-d}
\end{array}
\end{array}\right.
\end{gathered}
$$

Where $\mathrm{H}$ is the oil level for the bearing with oil bath lubrication, while for oil jet lubrication, $\mathrm{H}$ is at half of the diameter of the lowest rolling element and $M_{\text {drag }}$ should be multiplied by a factor of two.

It should be emphasized that in the two models above, the effect of the oil volume flow rate is not considered and the bearing is regared as full-lubricated. 
Theoretically, with more oil flow rate, the oil phase volume fraction inside the bearing cavity is higher, with more windage drag and churning losses.

\section{Parker model}

Parker [13] deduced an equation to calculate the oil percent volume in bearing cavity based on a range of experimental tests. The computer program SHABERTH was used to calculate the thermal performance of three selected ball bearings for the comparison [12]. The oil volume fraction was derived as a function of lubricant flow rate, shaft speed, and bearing pitch diameter.

$$
X C A V=10.0 \times 10^{6} \frac{W^{0.37}}{n d^{1.7}}
$$

Where $\mathrm{W}$ is the inlet oil flow, $\mathrm{cm}^{3} / \mathrm{min}, \mathrm{n}$ is the inner shaft speed, rpm, and $\mathrm{d}$ is the bearing pitch diameter, $\mathrm{mm}$. Depending on the oil/air volume ratio inside the bearing cavity, the effective density and viscosity of the equivalent fluid could therefore be expressed as

$$
\begin{aligned}
\rho_{\text {eff }} & =\left(\rho_{\text {oil }} \times \text { oilvolume }+\rho_{\text {air }} \times \text { airvolume }\right) / \text { totalvolume } \\
& \cong \rho_{\text {oil }} \times \frac{\text { oilvolume }}{\text { totalvolume }}=\rho_{\text {oil }} \times X C A V \\
\mu_{e f f} & =\left(\mu_{\text {oil }} \times \text { oilvolume }+\mu_{\text {air }} \times \text { airvolume }\right) / \text { totalvolume } \\
& \cong \mu_{\text {oil }} \times \frac{\text { oilvolume }}{\text { totalvolume }}=\mu_{\text {oil }} \times X C A V
\end{aligned}
$$

In the progarm SHABERTH, all hydraulic losses are named drag loss and accounted by the model of one isolated element in an uniform fluid.

$$
F_{r}=\frac{1}{2} C_{d} \rho V^{2} A
$$

Where $F_{r}$ is the drag force, $N, \rho$ the mass density of the fluid, $\mathrm{kg} / \mathrm{m}^{3}, \mathrm{~V}$ the velocity at which the body is traveling, $\mathrm{m} / \mathrm{s}$, and $A$ the frontal area of the body to the flow direction, $m^{2}$. Here the drag coefficient $C_{d}$ plays a dominant part in the drag force calculation, as a function of the Reynolds number, both 


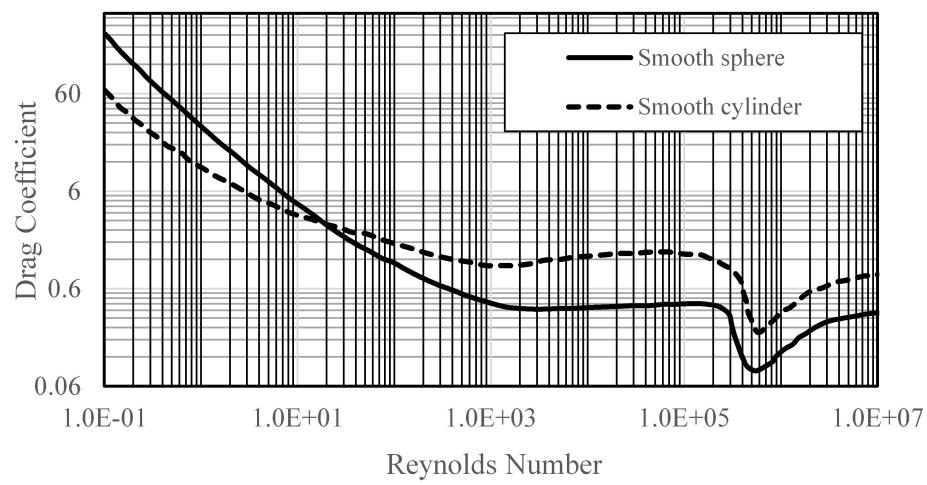

Figure 1: Drag coefficient of the isolated sphere and cylinder [20]

for a smooth cylinder and a smooth sphere, as shown in Fig. 1 [19]. Since all the analysis are performed using MIL-L-23699 type lubricants, the Parker model should not be used with lubricants whose properties vary significantly from MIL-L-23699.

\section{Numerical-based drag and churning losses model}

Thanks to the development of computer science and computational fluid dynamics (CFD) [21], the numerical simulation is becoming an increasingly approach that can help the investigtaion in drag and churning losses in roller bearings [22]. The authors analyzed numerically one configuration with several in-line finite-length circular cylinders sandwiched by two flat walls, with periodic

boundary conditions (Fig. 2) [14], which represents a simplified approach close to the real bearing. Different factors, e.g. roller rotational speed, roller orbital speed, fluid properties, and roller geometry parameters, are studied to verify their effects to the drag and churning losses.

\section{Drag force on the roller}

For the drag force acting on the roller in bearings, a simple expression for the drag coefficient versus the Reynolds number is as shown below [15], based 


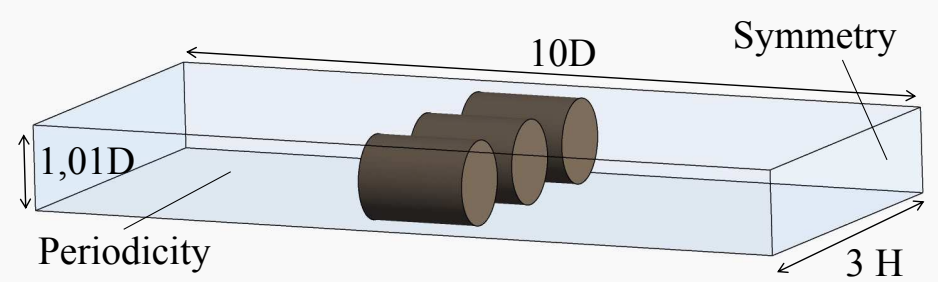

Figure 2: Geometry and boundary conditions in the numerical investigation

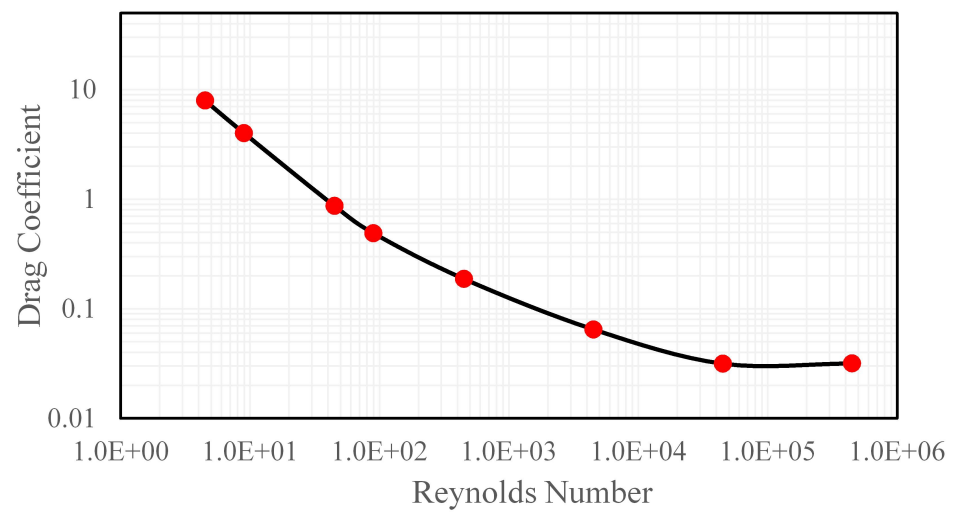

Figure 3: Drag coefficient of the roller in bearings as a function of the Reynolds number

on the line in the Fig. 3.

$$
C_{d}=\frac{F_{r}}{2 \rho V^{2} A}=35.02 \times R e^{-0.9899}+0.05975
$$

\section{Churning moments on the roller}

Based on the numerical data, two individual formulations are proposed to evaluate churning moment components on the roller cylindrical surface and two circular ends, respectively. For either the cylindrical surface or the free end, the moment is combined with two parts, the static component $\left(M_{c 0}, M_{e 0}\right)$ which is caused by the roller rotating, and the dynamic component $\left(M_{c s}, M_{e s}\right)$ as a result of the roller orbiting along the runway [14]. For the churning moment on 
the cylindrical surface,

$$
M_{c}=M_{c 0}+M_{c s}
$$

The static component is from Rumbarger [12], and the most important factor is the calculation of friction wall shear stresses on the element surface.

$$
M_{c 0}=\tau A_{c} r
$$

where $A_{c}$ is the surface area and $r$ the reference radius from the center of rotation. The wall shear stress, $\tau$, is given by:

$$
\tau=\frac{1}{2} f \rho U^{2}
$$

145 with $\rho$ the mass density; $U$ the mass average velocity of the fluid; and $f$ the friction factor which is defined for vortex turbulent flow (for $T a>41$ ):

$$
\frac{f}{f_{L}}=1.3\left(\frac{T a}{41}\right)^{0.539474}
$$

where $T a=\frac{\rho \omega r c}{\mu} \sqrt{\frac{c}{r}}$ is the Taylor number, and $f_{L}=16 / R e$ the laminar friction factor when $R e<2500$.

The dynamic component is developed from the numerical simulation about the interaction between the fluid and the rollers (Fig. 4).

$$
M_{c s}=C_{c s} \rho V \omega A_{c} r^{2} \mu^{0.818}, C_{c s}=30.745
$$

And the formula of churning moment on the roller end should be

$$
M_{e}=M_{e 0}+M_{e s}
$$

The static component is from von Karman [8], characterized by the flow over a disk rotating in a fluid initially at rest.

$$
M_{e 0}=\frac{1}{2} C_{e 0} \rho \omega^{2} r^{5}
$$


where $C_{n}= \begin{cases}3.87 / R e^{0.5} & \text { if } R e<300,000 \\ 0.146 / R e^{0.2} & \text { if } R e>300,000\end{cases}$

And the dynamic component could be expressed by an equation of the form:

$$
M_{e s}=C_{e s} \rho V \omega A_{e} r^{2} \mu^{0.603}, C_{e s}=4.174
$$

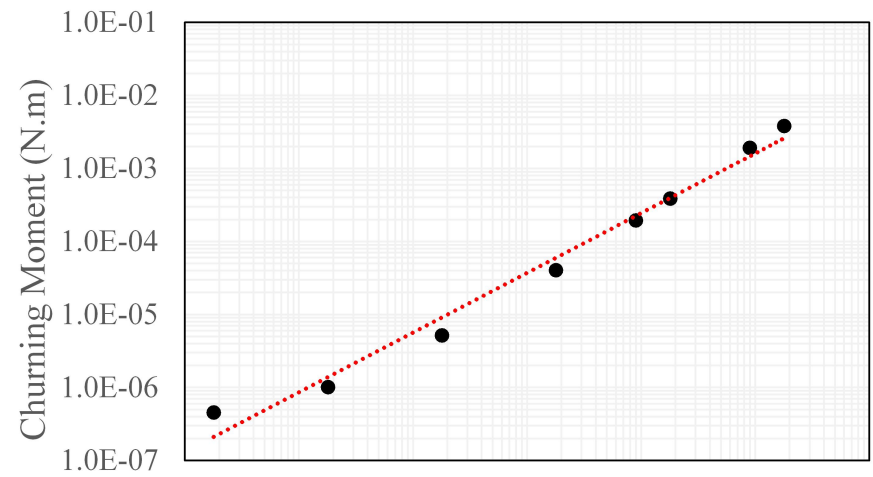

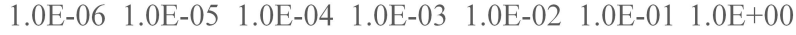

Fluid Viscosity (kg.m-1.s-1)

(a) Cylindrical surface

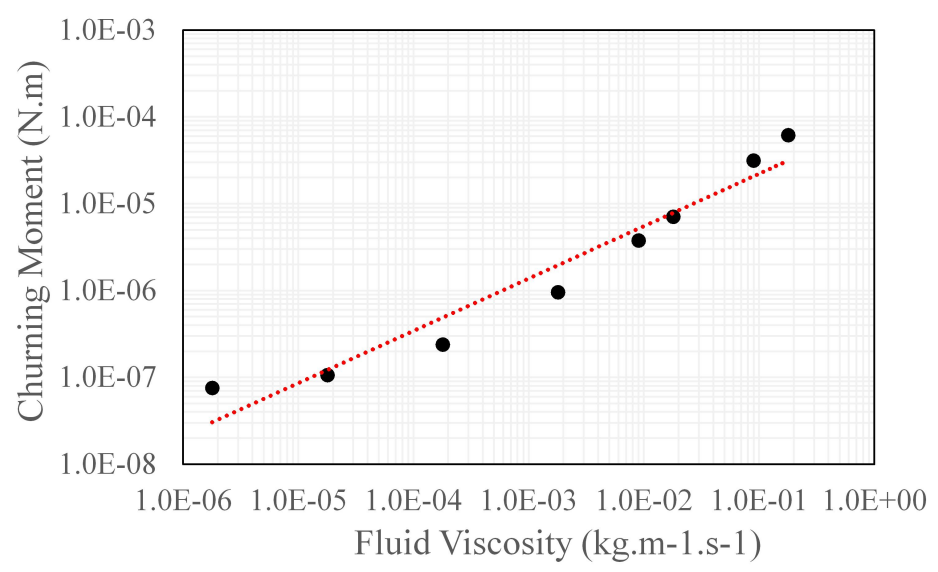

(b) Roller end

Figure 4: Churning moment as a function of the fluid viscosity in roller bearings 


\section{Oil volume fraction inside the bearing cavity}

The above formulas are obtained in a one-phase environment, whereas the fluid inside the bearing cavity is oil/air mixture and its equivalent fluid proper-

$$
X C A V=2.58 \times 10^{4} \times \frac{\left(\omega_{i}-0.1972 \omega_{r e}\right)^{1.313} W^{0.5} \mu}{\left(\omega_{i}+\omega_{o}\right)\left(\omega_{i}+1.768 \omega_{c}\right) d_{m}^{1.7}}
$$

Where $\omega_{i}, \omega_{o}, \omega_{c}$ are the inner ring, outer ring and the cage rotational speed, respectivly, rpm. $\omega_{r e}$ is the inner ring-cage relative speed, rpm. $W$ is the oil volum flow, $\mathrm{cm}^{3} / \mathrm{min} . \quad \mu$ is the oil dynamic viscosity, Pa.s. And $d_{m}$ is the bearing pitch diameter, $m m$. 

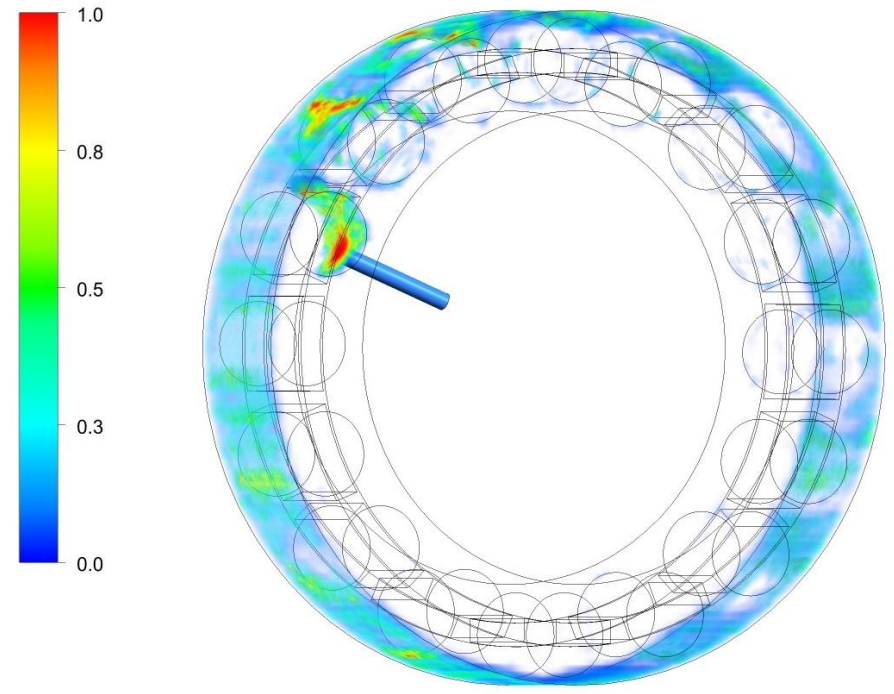

Figure 5: Oil volume fraction distribution along the bearing circumference with under-race lubrication

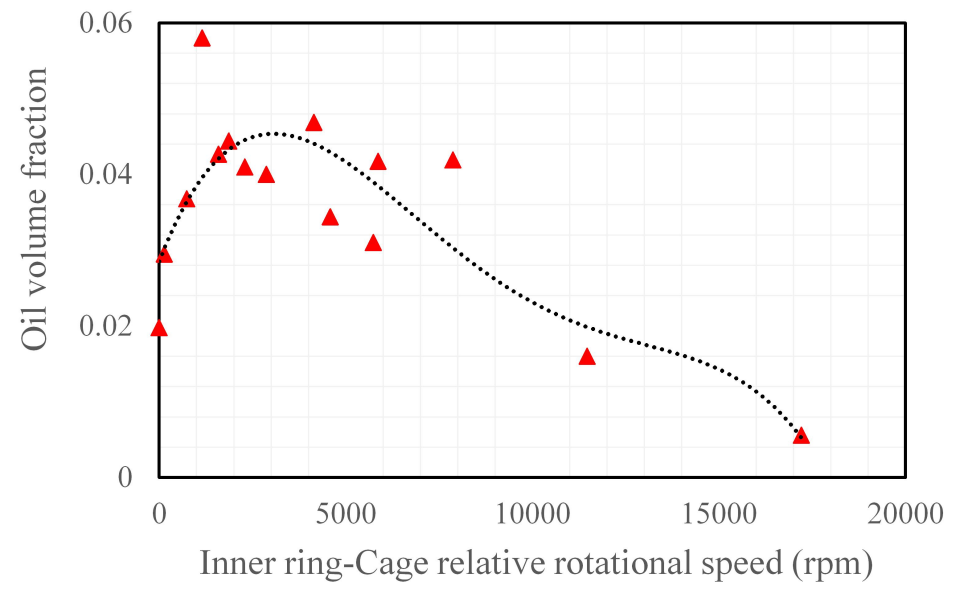

Figure 6: The average oil volume fraction as a function of the inner ring-cage relative speed 
Table 1: Roller bearing specifications

\begin{tabular}{cl}
\hline Pitch diameter $(\mathrm{mm})$ & 48.5 \\
Bearing width $(\mathrm{mm})$ & 14 \\
Number of rollers & 16 \\
Roller diameter $(\mathrm{mm})$ & 7.14 \\
Roller length $(\mathrm{mm})$ & 10 \\
Radial clearance $(\mu \mathrm{m})$ & 80 \\
\hline
\end{tabular}

With the formulas for drag force and churning moments calculation in roller bearings, and the oil volume fraction predicting equation, the total drag and churning losses in roller bearing with under-race lubrication could be obtained.

\section{Example drag and churning losses analysis}

According to the equations in frame of reference about drag and churning losses analysis method used by Palmgren, SKF and Parker, and the method developed by the authors based on the numerical investigation, functions are built for each model. To validate the accuracy of the proposed numerical drag and churning losses prediction method, results of these four models are calculated and compared. The cylindrical roller bearing specification used for the analysis

195 is listed in Table 1. The lubricant oil used here is respected to the MIL-L-23699 type lubricant oil with a popular trade name Mobile Jet 2. Respectively, the lubricant oil density is $976 \mathrm{~kg} / \mathrm{m}^{3}$ and the viscosity is $0.018 \mathrm{~kg} /(\mathrm{m} . \mathrm{s})$. The oil is supplied through the inner ring and the oil injection velocity is $20 \mathrm{~m} / \mathrm{s}$. The calculation results will be presented in detail.

\subsection{Bearings with inner ring rotating}

The three existing models (Palmgren, SKF, Parker) were built according to a series of experimental tests for bearing with inner ring rotating, having a 
certain accuracy for its specific operating conditions. For example, the SKF model is developed for bearings lubricated by the oil bath method, partially submerged or, in special situations, completely submerged. Despite the effect of oil volume flow rate is not considered, it could be assumed that the bearing is full-lubricated or, excessive-lubricated.

\section{The effect of bearing rotating speed}

The bearing rotating speed has a very significant effect on the roller bearing power loss so that drag and churning losses changing with the rotating speed are analyzed first. Fig. 7 illustrates the calculation results of different drag and churning losses prediction models. The oil volume flow rate is set as 2000 $\mathrm{cm}^{3} / \mathrm{min}$ and the inner ring rotating speed ranges from 2000 to $80000 \mathrm{rpm}$. It could be found that the SKF model gets the largest predicted hydraulic losses and Palmgren model is the lowest for most inner ring rotating speeds. This results correspond with the fact that the bearing in the SKF model is assumed to be full-lubricated. Noting when the bearing rotating speed reaches up to $80000 \mathrm{rpm}$, the oil flow rate $2000 \mathrm{~cm}^{3} / \mathrm{min}$ is not enough for lubricating. Thus the SKF model has the largest predicted value. In addition, the numerical model results match well with the Parker model, which is proposed from the comparison of bearing thermal performance over a range of test conditions. This demonstrates that the numerical model is reliable and valuable in terms of the total drag and churning losses prediction.

If we increase the oil volume flow rate up to $3000 \mathrm{~cm}^{3} / \mathrm{min}$, as shown in Fig. 8, only the results of the Parker model and numerical model could be changed, which take this factor into account. For the bearing rotating speed from $2000 \mathrm{rpm}$ to $80000 \mathrm{rpm}$, results of the SKF model, Parker model and numerical model are similar, and larger than that of the Palmgren model. In this condition, the bearing is regarded as sufficient-lubricated. If the oil volume 230 flow rate is increased further to $4000 \mathrm{~cm}^{3} / \mathrm{min}$, as shown in Fig. 9, the bearing is over-lubricated and the result of the numerical model is obviously larger than the other three models. It means that larger amounts of lubricant oil flow can definitely lead to larger heat generation. 


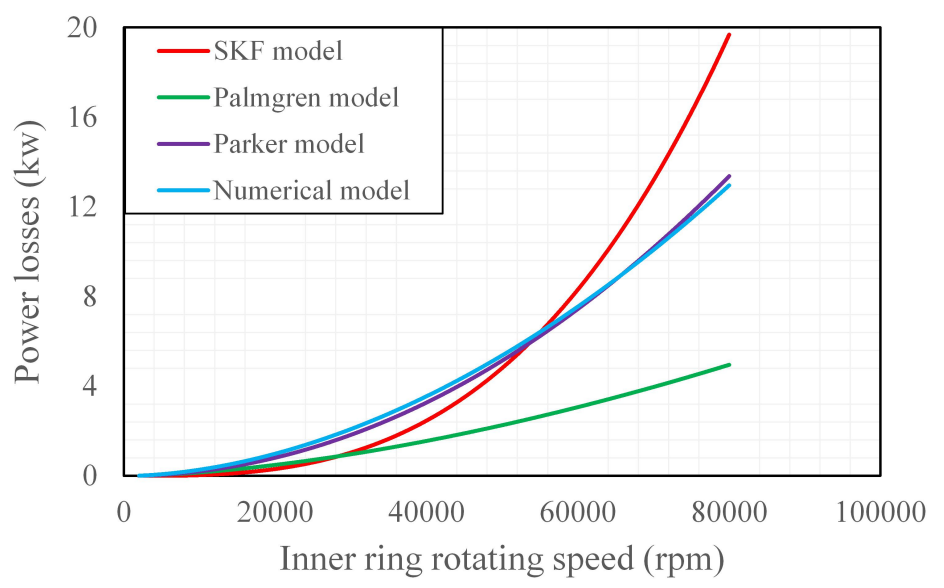

Figure 7: Hydraulic losses from different models at different inner ring rotating speed (Oil flow rate $2000 \mathrm{~cm}^{3} / \mathrm{min}$

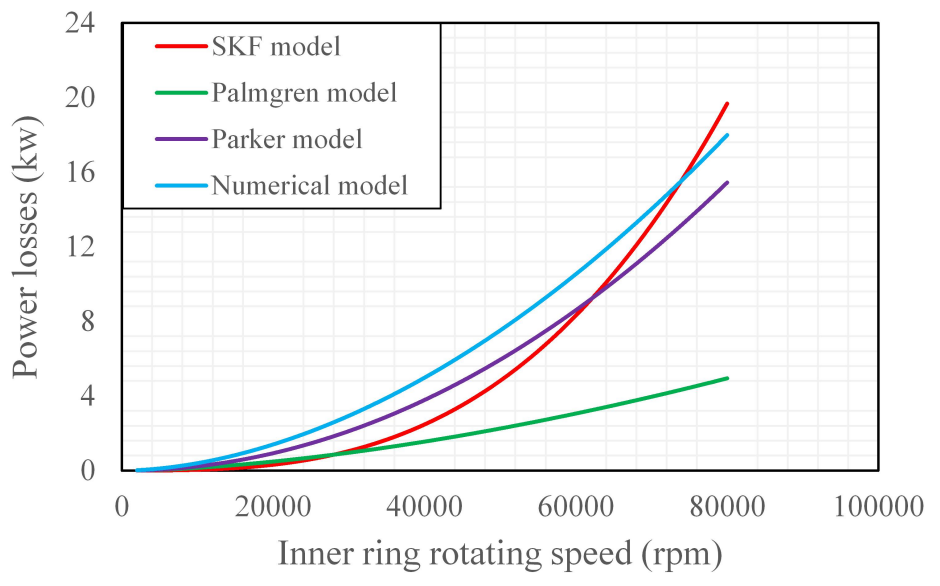

Figure 8: Hydraulic losses from different models at different inner ring rotating speed (Oil flow rate $3000 \mathrm{~cm}^{3} / \mathrm{min}$ ) 


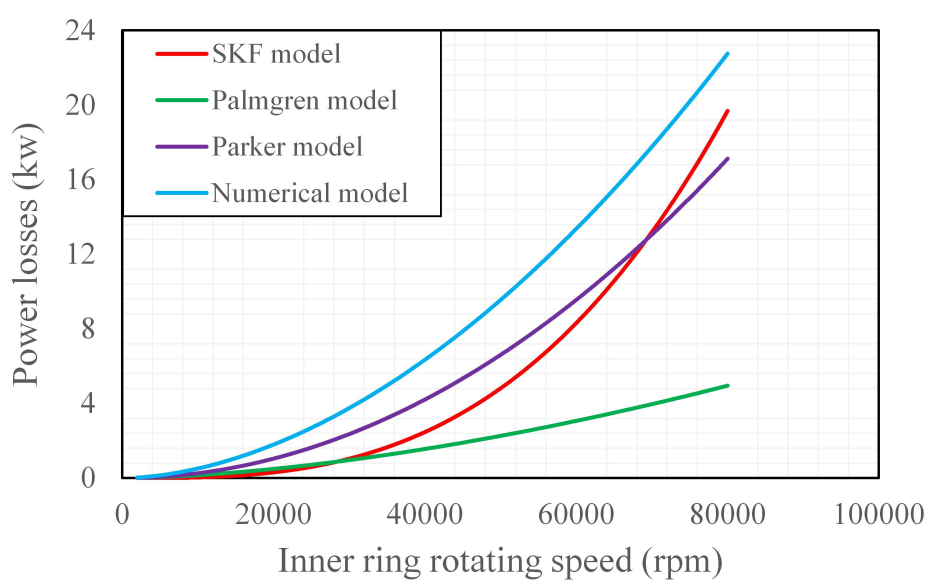

Figure 9: Hydraulic losses from different models at different inner ring rotating speed (Oil flow rate $4000 \mathrm{~cm}^{3} / \mathrm{min}$ )

\section{The effect of the oil flow rate}

Now that a large amount of oil volume flow leads to a higher power loss and too small oil flow may cause a lubrication failure, a sufficient assessment of the lubricated bearing is of particular importance. Fig. 10 shows results of these four models with a fixed bearing rotating speed $72200 \mathrm{rpm}$, as a function of the oil volume flow rate. The SKF model and Palmgren model are constant which are regarded as full-lubricated by default. The results of the Parker model and the numerical model are close and increase obviously with the increase of the oil flow rate.

Based on the above analysis, it is demonstrated that the numerical model for drag and churning losses estimation in roller bearings is reliable and reasonable. The predicted result of the SKF model is usually a little too high while the Palmgren model is always too low. For the Paker model, its result is close to the numerical one, but it can't distinguish the drag and churning effects, and it can't be used directly for the counter-rotating roller bearing with under-race lubrication.

As shown in the Fig. 11, the total hydraulic losses, caused by the roller rotating and translating in the fluid environment, are contributed by three parts, 


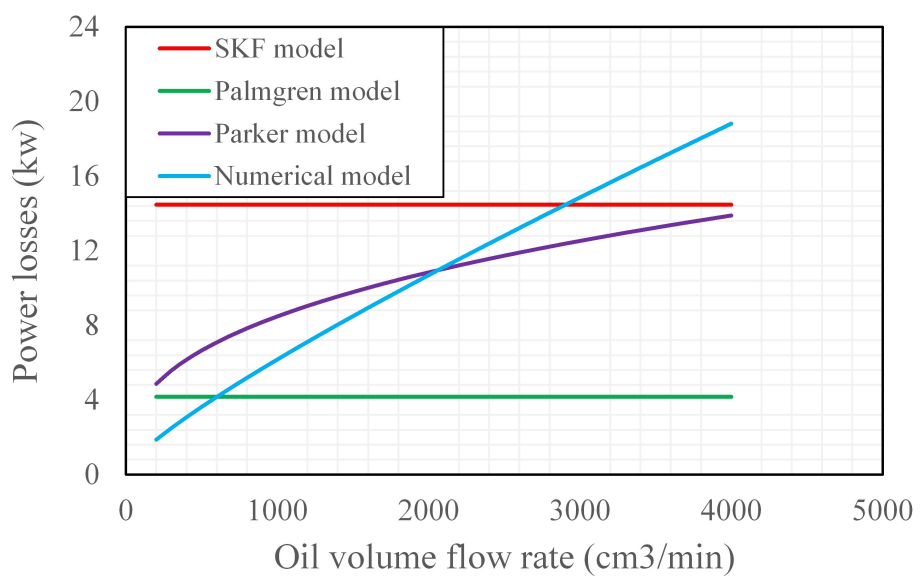

Figure 10: Hydraulic losses from different models at different oil flow rate (Inner ring rotating $72200 \mathrm{rpm})$

drag loss, churning loss on the cylindrical surface, and churning loss on the free end. The churning loss on the cylindrical surface takes the most proportion of the total hydraulic losses and the other two parts only take a small percentage.

255 This is disagreed with the previous research which named the total hydraulic losses as drag loss.

\subsection{Counter-rotating roller bearings}

Advanced engine configuration studies have shown large advantages for engine with counter-rotating spools with intershaft counter rotating roller bearings [27]. Whereas a severe challenge is met for its thermal behavior analysis using traditional methods [28]. For example, with the additional rotating of the outer ring, the SKF model and the Palmgren model fail and the oil volume fraction inside the bearing cavity can't be estimated by the Parker formula. Since the effect of the outer ring rotating is considered in the numerical model formulation, it could be used directly for the drag and churning losses prediction in counter rotating roller bearings with under-race lubrication.

\section{The effect of rotating speeds}

Fig. 12 presents different parts of the hydraulic losses in roller bearing with 


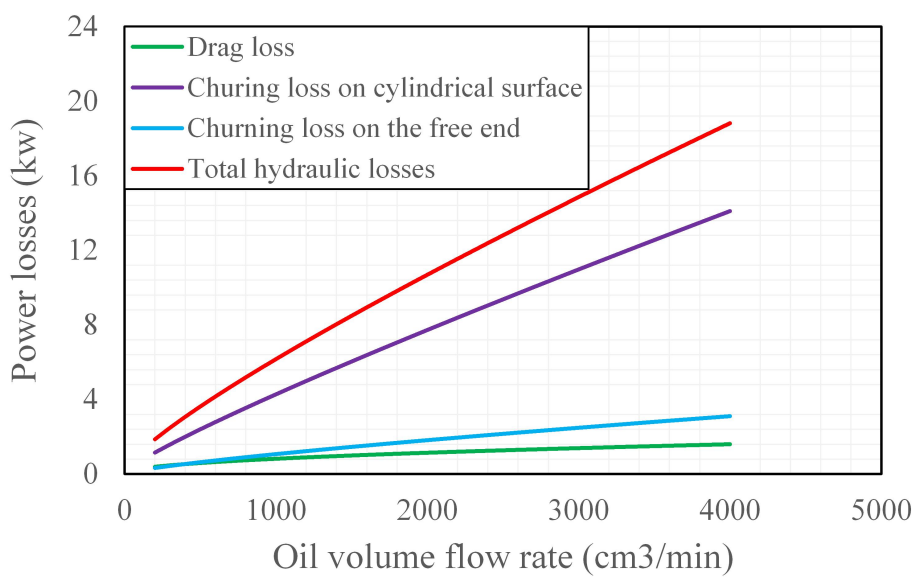

Figure 11: Partial of hydraulic losses at different oil flow rate (Inner ring rotating $72200 \mathrm{rpm}$ )

different outer ring rotational speeds. The inner ring rotational speed is 28000 $\mathrm{rpm}$ and the oil volume flow rate is $2000 \mathrm{~cm}^{3} / \mathrm{min}$. The rotating direction of the rings is adverse. It could be found that the lines are seperated to two regimes when going from 0 to large outer-ring rotational speed. In the low speed range, the average oil volume fraction inside the bearing decreases slowly, while churning losses increase quickly. The drag loss reduces as a result of the decrease of the cage speed. When the outer ring rotating speed is about 21000 rpm, the drag loss may even disappear with a hovering cage [29].

In the high speed range, the cage rotates in the outer ring's direction and the relative inner ring-cage speed increases, leading to a dramatic decrease of the oil volume fraction. Though all bearing components rotating speeds become quicker, the total hydraulic losses reduce. It may be confirmed that the bearing is poor-lubricated in this range. In most counter rotating conditions, the bearing hydraulic losses are higher than that with only inner ring rotating.

In addition, in turbine engine there are two kinds of inter-shaft bearing mounting configurations, named the natural arrangement and the inverted one 285 [30], as shown in Fig. 13. The former supports the high speed rotor on the outer ring and the low speed shaft on the inner ring, while the latter is opposite. To present the difference of these two configurations, another condition is analyzed 


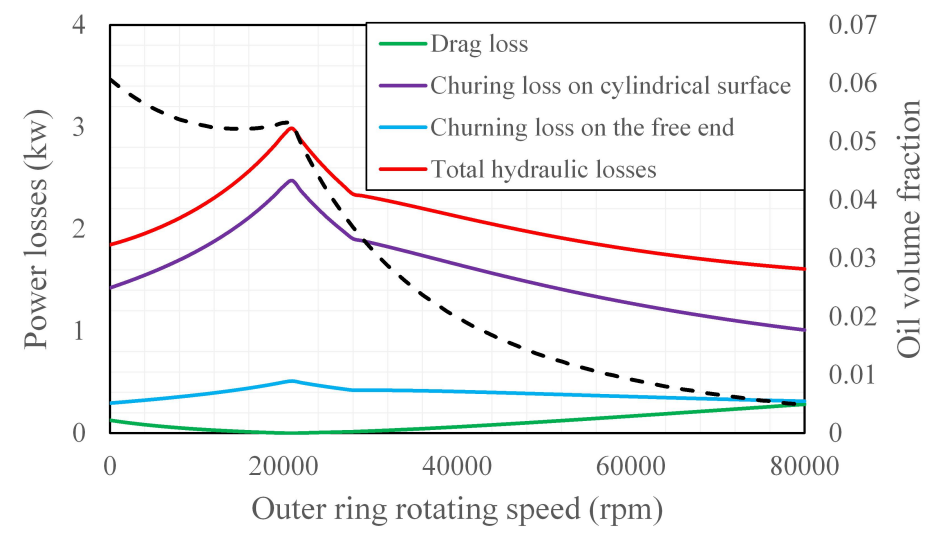

Figure 12: Partial of hydraulic losses with different outer ring rotating speeds (Inner ring rotating $28000 \mathrm{rpm}$ )

with different inner ring rotating speeds, as shown in Fig. 14. The outer ring rotating speed is fixed to $28000 \mathrm{rpm}$ and the oil volume flow rate is 2000 $\mathrm{cm}^{3} / \min$.

It could also be found that, the lines are also seperated to two regimes obviously. In the low speed range, the oil volume fraction increases when the inner ring rotating speed is lower than $38000 \mathrm{rpm}$. After that, the cage rotating direction changes and begins to increase, resulting in the decrease of the oil volume fraction. The total hydraulic losses keep to increase during all this process.

\section{The effect of the oil flow rate}

Fig. 15 shows the total hydraulic losses and average oil volume fraction with different oil volume flow rate, in the natural configuration and the inverted one, respectively. The two rings' rotating speed combination is 28000/10000 rpm. For the natural configuration, with a higher outer ring rotating speed, the cage rotates in the outer ring's direction, which increases the relative inner ringcage speed, being against to the oil volume fraction. The lower oil distribution inside the bearing leads to a lower hydraulic losses for the bearing in the natural configuration. However, it should be drawed attention whether the bearing is sufficient lubricated and cooled or not, with complete thermal analysis of the 


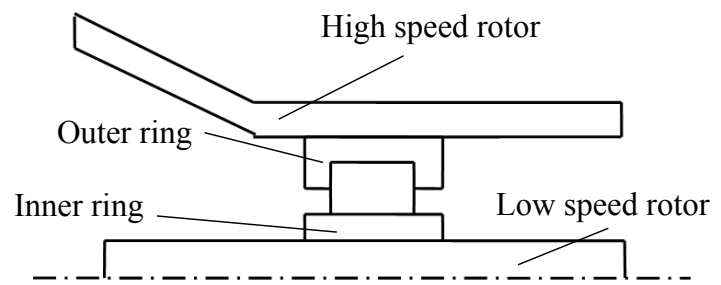

Inner ring on low speed rotor

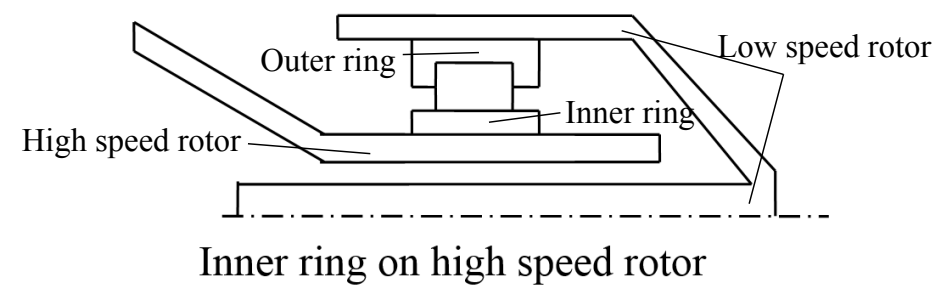

Figure 13: The natural (top) \& inverted (bottom) configurations

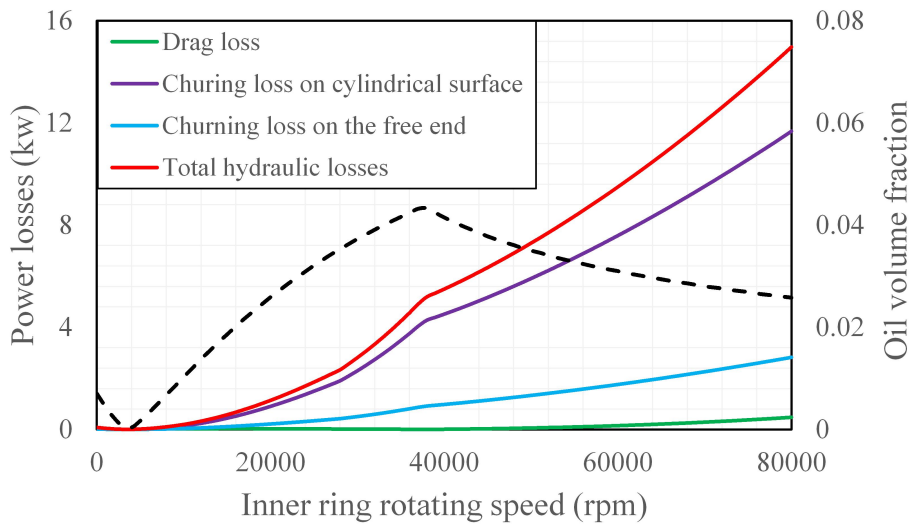

Figure 14: Partial of hydraulic losses with different inner ring rotating speeds (Outer ring rotating $28000 \mathrm{rpm}$ ) 


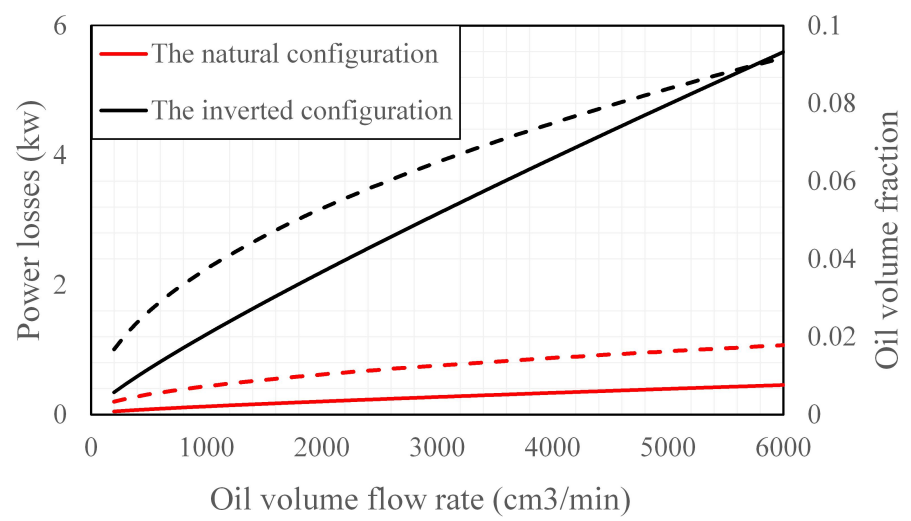

Figure 15: Hydraulic losses with different oil volume flow rate in different configurations (28000/10000 rpm)(The full line for hydraulic losses, the dash line for oil volume fraction)

bearing.

If the bearing rotating combination is changed to $28000 / 20000 \mathrm{rpm}$, as shown in Fig. 16, it is illustrated that the loss difference between the two configurations decreases as a result of the reduce of the rotating speed difference. The average oil volume fraction is still a key element in determining the total hydraulic losses.

\section{Conclusions and future work}

In this paper an investigation is made in order to validate the numerical model for the estimation of drag and churning losses in high speed roller bearings, which is developed by the authors in previous research. Three existing models, e.g. the SKF model, the Palmgren model and the Parker model, are used here for the validation. Due to coming from experimental tests, the three existing models are reliable for their specific conditions. So that in the first step, the total drag and churning losses (or named hydraulic losses) for the bearing with only inner ring rotating are calculated and results of all four models are compared. Results demonstrate that the numerical model agrees well with the Parker model for most calculated conditions, and is close to the SKF model only if the bearing is full-lubricated. Noting that the oil flow rate is not considered 


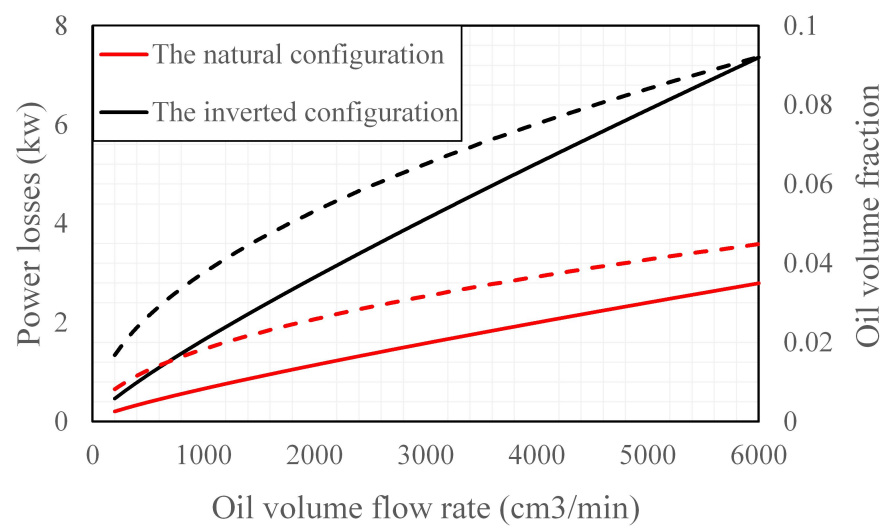

Figure 16: Hydraulic losses with different oil volume flow rate in different configurations $(28000 / 20000 \mathrm{rpm})$ (The full line for hydraulic losses, the dash line for oil volume fraction)

in the SKF model and the Palmgren model. In addition, the numerical model could distinguish different contributions of the hydraulic losses, unlike the other three models.

Then the numerical model is employed to estimate drag and churning losses in counter rotating roller bearing with under-race lubrication, which is beyond the capacity of the other three models. Results show that churning loss on the roller cylindrical surface takes the most part of the total hydraulic losses, while the drag loss occupies a rather small proportion. Compared with the inverted configuration with faster-rotating inner ring, the losses of the bearing in the natural configuration is smaller, with relative lower average oil volume fraction inside the bearing. This work proposes an effective method for the drag and churning losses estimation for high speed roller bearings, especially for intershaft supporting bearings in modern multi-shaft turbine engine.

Our ongoing studies on this topic focuses on the complete thermal analysis of roller bearings, taking account the entire power losses, as well as heat transfer between different components and the oil system. An experimental equipment will be built to verify the difference between the natural configuration and the inverted one. 


\section{References}

[1] S. Biswas, J. Kumar, V. Satishkumar, N. Babu SN, Failure analysis of a squirrel cage bearing of a gas turbine engine, in: Advances in Structural Integrity, 2018, pp. 117-125. doi:10.1007/978-981-10-7197-3_10.

[2] E. Kuznetsov, S. Glavatskih, Dynamic characteristics of compliant journal bearings considering thermal effects, Tribology International 94 (2016) 288305. doi:10.1016/j.triboint.2015.08.018.

[3] Y. Marchesse, C. Changenet, F. Ville, Numerical investigations on drag coefficient of balls in rolling element bearing, Tribology Transactions 57 (2014) 778-785. doi:10.1080/10402004.2014.911399.

[4] Y. Marchesse, C. Changenet, F. Ville, P. Velex, Numerical investigation of the cage and rings influence on the ball drag coefficient, in: STLE 70th Annual Meeting \& Exhibition, 2015.

[5] C. M. Fernandes, P. M. Marques, R. C. Martins, J. H. Seabra, Gearbox power loss. part i: Losses in rolling bearings, Tribology International 88 (2015) 298-308. doi:10.1016/J.TRIBOINT . 2014.11.017.

[6] S.-W. Hong, V.-C. Tong, Rolling-element bearing modeling: A review, International Journal of Precision Engineering and Manufacturing 17 (2016) 1729-1749. doi:10.1007/s12541-016-0200-z.

[7] A. Linjamaa, A. Lehtovaara, R. Larsson, M. Kallio, S. Söchting, Modelling and analysis of elastic and thermal deformations of a hybrid journal bearing, Tribology International 118 (2017) 451-457. doi:10.1016/J.TRIBOINT. 2017.02 .029 .

365

[8] I. Chueshov, I. Lasiecka, Von karman models with rotational forces, in: Springer Monographs in Mathematics, Springer New York, 2010, pp. 129194. doi:10.1007/978-0-387-87712-9_3. 
[9] S. Laruelle, C. Fossier, C. Changenet, F. Ville, S. Koechlin, Experimental investigations and analysis on churning losses of splash lubricated spiral bevel gears, Mechanics \& Industry 18 (2017) 412. doi:10.1051/meca/ 2017007.

[10] J. Liebrecht, X. Si, B. Sauer, H. Schwarze, Investigation of drag and churning losses on tapered roller bearings, Journal of Mechanical Engineering 61 (2015) 399-408. doi:10.5545/sv-jme.2015.2490.

[11] L. Yaguo, S. Jieyang, L. Zhenxia, H. Jianping, The improvement of air/oil separator performance in the aero-engine lubrication system, in: ASME Turbo Expo 2017: Turbomachinery Technical Conference and Exposition, 2017, p. V009T27A017. doi:10.1115/gt2017-64327.

[12] B. D. Nicholson, G. D. Givan, K. L. Thompson, J. Mason, P. K. Gupta, H. K. Trivedi, Assessment of bearing heat generation prediction by the program adore with respect to experimental results and shaberth predictions, in: ASME Turbo Expo, 2017, p. V001T01A001. doi:10.1115/ gt2017-63010.

[13] R. J. Parker, Comparison of predicted and experimental thermal performance of angular-contact ball bearings, NASA Technical Paper 2275 (1984) $16 \mathrm{P}$.

[14] W. Gao, D. Nelias, N. Boisson, Y. Lyu, Model formulation of churning losses in cylindrical roller bearings based on numerical simulation, Tribology Internationaldoi:10.1016/j.triboint.2018.02.003.

[15] W. Gao, D. Nelias, Y. Lyu, N. Boisson, Numerical investigations on drag coefficient of circular cylinder with two free ends in roller bearings, Tribology International 123 (2018) 43-49. doi:10.1016/j.triboint.2018.02.044.

[16] G. Wenjun, L. Zhenxia, L. Yaguo, Development and application of general software of bearing chamber thermal analysis, Aeronautical Computer 
Technique 1 (2013) 106-109. doi:10.3969/j.issn.1671-654X.2013.01. 027.

[17] M. TU, Validation and modeling of power losses of nj406 cylindrical roller bearings, Master's thesis, KTH, Machine Design (Dept.) (2016).

[18] C. M. Fernandes, P. M. Amaro, R. C. Martins, J. H. Seabra, Torque loss in thrust ball bearings lubricated with wind turbine gear oils at constant temperature, Tribology International 66 (2013) 194-202. doi:10.1016/j . triboint.2013.05.002.

[19] A. Hölzer, M. Sommerfeld, New simple correlation formula for the drag coefficient of non-spherical particles, Powder Technology 184 (3) (2008) 361-365. doi:10.1016/j.powtec . 2007 .08. 021.

[20] L. Yaguo, Z. Jingyu, L. Zhenxia, R. Guozhe, Numerical study on the effect of oil removal from aero-engine bearing chamber and improvement, in: STLE 71th Annual Meeting \& Exhibition, 2016.

[21] M. Deligant, P. Podevin, G. Descombes, Cfd model for turbocharger journal bearing performances, Applied Thermal Engineering 31 (5) (2011) 811-819. doi:10.1016/j.applthermaleng. 2010.10.030.

[22] W. Wu, C. Hu, J. Hu, S. Yuan, R. Zhang, Jet cooling characteristics for ball bearings using the vof multiphase model, International Journal of Thermal Sciences 116 (2017) 150-158. doi:10.1016/J. IJTHERMALSCI.2017. 02.014 .

[23] W. Wu, C. Hu, J. Hu, S. Yuan, Jet cooling for rolling bearings: Flow visualization and temperature distribution, Applied Thermal Engineering 105 (2016) 217-224. doi:10.1016/j .applthermaleng. 2016.05.147.

[24] D. N. Wenjun GAO, Modelling of windage and churning loss of lubrication oil in high speed roller bearing, Ph.D. thesis, INSA de Lyon (2018). 
[25] K. Yan, Y. Wang, Y. Zhu, J. Hong, Q. Zhai, Investigation on heat dissipation characteristic of ball bearing cage and inside cavity at ultra high rotation speed, Tribology International 93 (2016) 470-481. doi: 10.1016/j.triboint.2015.09.030.

[26] G. Cavallaro, D. Nelias, F. Bon, Analysis of high-speed intershaft cylindrical roller bearing with flexible rings, Tribology transactions 48 (2) (2005) 154-164. doi:10.1080/05698190590923851.

[27] P. Zhu, Z. Liu, W. Gao, J. Zhao, Y. Lu, et al., Calculation study of heat generation in counter-rotating cylindrical roller bearing, in: Asia-Pacific International Symposium on Aerospace Technology, 2015, p. 91.

[28] T. D. Swanson, G. C. Birur, Nasa thermal control technologies for robotic spacecraft, Applied thermal engineering 23 (9) (2003) 1055-1065. doi: $10.1016 / \mathrm{s} 1359-4311(03) 00036-\mathrm{x}$.

[29] C. G. Cameron, A. Karpatne, J. Sirohi, Performance of a mach-scale coaxial 435 counter-rotating rotor in hover, Journal of Aircraft (2016) 746-755doi: 10.2514/1.c033442.

[30] K. Kumari, S. K. Pal, S. B. Singh, Friction stir welding by using counterrotating twin tool, Journal of Materials Processing Technology 215 (2015) 132-141. doi:10.1016/j.jmatprotec. 2014.07.031. 